\title{
Thermoelectric properties of barium doped calcium cobaltite obtained by simplified chemical route
}

\author{
R.A.M.Machado ${ }^{1}$ M.V. Gelfuso ${ }^{1 *}$, D. Thomazini ${ }^{1}$ \\ ${ }^{1}$ Federal University of Itajubá, Development of Functional Materials Group, \\ Av. BPS 1303, 37500-903, Itajubá, MG, Brazil
}

\begin{abstract}
Calcium cobaltite (CCO) thermoelectric ceramics in $\mathrm{Ca}_{3} \mathrm{Co}_{4} \mathrm{O}_{9}$ and $\mathrm{Ca}_{2.95} \mathrm{Ba}_{0.05} \mathrm{Co}_{4} \mathrm{O}_{9}$ compositions were produced by a simplified chemical route developed in this study. Undoped ceramics sintered at $1193 \mathrm{~K}$ for $12 \mathrm{~h}$ presented a bulk density equivalent to $77 \%$ of the theoretical density, one of the highest values ever found for conventionally sintered undoped calcium cobaltite. The presence of barium improved densification, reaching $80 \%$ of the theoretical density. Thermoelectric properties were discussed based on X-ray diffraction patterns, scanning electron micrographs, Seebeck coefficient, electrical and thermal conductivity. Electrical characterizations presented values of about 6200 and $7000 \mathrm{~S} / \mathrm{m}$ at $873 \mathrm{~K}$ for undoped and doped ceramics, respectively. However, all ceramics presented almost the same range of activation energy values, indicating the possibility of non-effective substitution through this methodology. The maximum global PF (power factor) was $0.10 \mathrm{~mW} \cdot \mathrm{m}^{-1} \cdot \mathrm{K}^{-2}$ for the densest undoped sample and an overall ZT (dimensionless figure of merit) of 0.07 for the undoped ceramic at $873 \mathrm{~K}$.
\end{abstract}

Keywords: thermoelectric ceramics, calcium cobaltite, barium.

\section{INTRODUCTION}

The dissipation of energy in the form of heat in automobiles, aircraft turbines, power plants, and factories is hardly recovered since there are several dissipative sources spread throughout the planet. This dissipation accounts for about $70 \%$ of the primary energy produced $[1,2]$. To minimize this problem, thermal-electric energy converters can be used to partially recover this energy and increase the efficiency of the system. Thus, locally, it is possible to have a thermoelectric generator (TEG) made of semiconducting materials, fitting perfectly into this scenario. The classic thermoelectric generators are produced from intermetallic compounds, such as lead and bismuth tellurides, and silicongermanium. The extent of their application is limited by some factors: decomposition at relatively low temperatures, low availability of precursors, high toxicity, and cost. Therefore, it has been preferred to use thermoelectric oxides to act as charge carriers, because they avoid most of the intermetallic compound limitations [2]. In 1997, the discovery of the thermoelectric (TE) properties of sodium cobaltite $\left(\mathrm{NaCo}_{2} \mathrm{O}_{4}\right)$ opened the way to the development of polycrystalline oxides capable of converting waste heat into usable energy [3]. Several high-performance thermoelectric oxides such as $\mathrm{Ca}_{3} \mathrm{Co}_{4} \mathrm{O}_{9}$ [4], $\mathrm{CaMnO}_{3}$ [5], $\mathrm{SrTiO}_{3}$ [6], and donor-doped $\mathrm{ZnO}$ [7] were produced and improved. Among these materials, layered cobalt oxide $\mathrm{Ca}_{3} \mathrm{Co}_{4} \mathrm{O}_{9}$, a $\mathrm{CoO}_{2}-$ based oxide, has been the concern of many studies since

*mvgelfuso@unifei.edu.br

@https://orcid.org/0000-0002-1533-0390 it is a p-type semiconductor with wide application in the conversion of residual thermal energy. $\mathrm{Ca}_{3} \mathrm{Co}_{4} \mathrm{O}_{9}$ structure consists of alternating layers of a distorted $\mathrm{CaO}-\mathrm{CoO}-\mathrm{CaO}$ rock salt-type layer (RS) and a $\mathrm{CdI}_{2}$-type $\mathrm{CoO}_{2}$ layer stacked in the direction of the c-axis. The bulk ceramics combine a high Seebeck coefficient around $125 \mu \mathrm{V} . \mathrm{K}^{-1}$ [4] with a relatively high electrical conductivity at room temperature.

Many approaches regarding the enhancement of TE performance of calcium cobaltite $(\mathrm{CCO})$ are conveyed through doping with alkaline metals $[8,9]$, alkaline earth metals [10-13], transition metals [14, 15], and/or rareearth metals [16] at $\mathrm{Ca}$ site. A comparison between some synthetic routes in the obtention of $\mathrm{Ca}_{3} \mathrm{Co}_{4} \mathrm{O}_{9}$ phase shows that attrition milling and chemical methods produce very reactive precursors, reflected in the decomposition of $\mathrm{CaCO}_{3}$ after a single heat treatment at $1023 \mathrm{~K}$ for $12 \mathrm{~h}$. The attrition milling and the classical solid-state methods still contain small amounts of $\mathrm{Ca}_{3} \mathrm{Co}_{2} \mathrm{O}_{6}$ phase while the chemical method can produce near pure $\mathrm{Ca}_{3} \mathrm{Co}_{4} \mathrm{O}_{9}$ phase [17]. The synthesis of calcium cobaltite by chemical route has been preferred since the reactants are mixed in stoichiometric proportions, which increases the reaction rate, allowing the obtention of a homogeneous powder with nanoscale particle size [2]. However, the synthesis of CCO ceramics with good thermoelectric properties and high density is a challenge due to the plate-like morphology of its particles, which can compromise green bodies packing and densification. Many studies have shown that the preparation methods can drastically influence the final bulk properties of $\mathrm{CCO}$ ceramics $[17,18]$, but synthesis methods have not yet been enough explored. This work consists of the evaluation 
of the thermoelectric properties regarding the sintering conditions for undoped and $\mathrm{Ba}$-doped $\mathrm{Ca}_{3} \mathrm{Co}_{4} \mathrm{O}_{9}$ ceramics obtained through a simplified chemical route. The selection of barium ion as a dopant was justified by the enhancement of thermoelectric efficiency for $\mathrm{CCO}$ ceramics reported in literature obtained by solid-state reaction [10] and grain boundary segregation [11].

\section{EXPERIMENTAL}

Calcium carbonate $\left(\mathrm{CaCO}_{3}\right.$, Sigma-Aldrich, 99.0\%), cobalt(II) nitrate hexahydrate $\left[\mathrm{Co}\left(\mathrm{NO}_{3}\right)_{2} \cdot 6 \mathrm{H}_{2} \mathrm{O}\right.$, SigmaAldrich, $95.0 \%)$, and barium carbonate $\left(\mathrm{BaCO}_{3}\right.$, SigmaAldrich, $99.0 \%$ ), used as precursors, were mixed to prepare the compositions $\mathrm{Ca}_{3} \mathrm{Co}_{4} \mathrm{O}_{9}$ and $\mathrm{Ca}_{2.95} \mathrm{Ba}_{0.05} \mathrm{Co}_{4} \mathrm{O}_{9}$ via an alternative method. This simplified chemical route has been successfully used by our research group to prepare other electronic ceramics. In this methodology, only citric acid was used as a dissolving and chelating agent, differing from the sol-gel methodology in which ethylene glycol and/ or polyethylene glycol are used to polymerize the solution [12]. Cobalt nitrate was added to a $1 \mathrm{M}$ aqueous citric acid solution under magnetic stirring at $353 \mathrm{~K}$, until complete solubilization. Calcium carbonate and barium carbonate, the latter used for doping, were transferred to the beaker containing cobalt nitrate and citric acid solution under vigorous agitation. In this process, high effervescence and rapid color change from red to purple were observed. The purple solution was dried in an oven at $343 \mathrm{~K}$ until a foamy deep purple material was formed, which was manually ground to break the agglomerates. The calcination of the foam was carried out at $1073 \mathrm{~K}$ for $3.5 \mathrm{~h}$ in a furnace in an air atmosphere, as determined by differential thermal analysis (DTA, STA-449 F3, Netzsch). DTA was carried out in air up to $1273 \mathrm{~K}$ using an $\mathrm{Al}_{2} \mathrm{O}_{3}$ crucible, with a heating rate of $10 \mathrm{~K} / \mathrm{min}$ and natural furnace cooling. Identical heating and cooling conditions were adopted for calcination. The calcined foams were manually ground aided by a porcelain mortar and uniaxially pressed at $100 \mathrm{MPa}$ into discs of 12 $\mathrm{mm}$ in diameter, producing samples approximately $1 \mathrm{~mm}$ thick. Undoped (P) and doped (B) samples were sintered in air at $1173 \mathrm{~K}$ for $12 \mathrm{~h}(\mathrm{P}-1173 / 12$; B-1173/12) and $24 \mathrm{~h}(\mathrm{P}-$ $1173 / 24$; B-1173/24), and at $1193 \mathrm{~K}$ for $12 \mathrm{~h}(\mathrm{P}-1193 / 12$; B-1193/12) with a heating rate of $10 \mathrm{~K} / \mathrm{min}$ and natural furnace cooling. Sintering time and temperature were chosen based on previous works that evaluated the influence of these parameters on both doped and undoped ceramics $[10,17,19]$.

The structural analysis of the calcined powders and sintered samples was done through X-ray diffraction (XRD) analysis (D8 Advance, Bruker) at room temperature $(\mathrm{CuK} \alpha$ radiation) with $2 \theta$ ranging between $10^{\circ}$ and $50^{\circ}$, step of $0.02^{\circ}$, and exposure time of $1 \mathrm{~s}$. Microstructural observations were performed by scanning electron microscopy (SEM, Phenom Pro-X, Thermo Fisher Sci.) coupled with energy dispersive spectrometry (EDS). Average particle and grain size were obtained through image analysis using SEM images aided by ImageJ software. Apparent density (Q) of the samples was calculated by Archimedes method, based on ASTM B962-17 standard, which states that sintered parts cannot have their volumes accurately measured using micrometers or calipers [20]. Electrical conductivity $(\sigma)$ measurements were conducted by the standard 4-probe DC method (SB-01, WT Ind.), using the sintered samples shaped in the form of a rectangular prism of about $10 \times 2 \times 1 \mathrm{~mm}$ in the air from room temperature up to $873 \mathrm{~K}$, with a heating rate of $1 \mathrm{~K} / \mathrm{min}$ and temperature gradient lower than $1 \mathrm{~K}$. Seebeck coefficient (S) was measured after 5 min of steady-state using the same sample setup conditions for $\sigma$ measurement, with a temperature gradient of $5 \mathrm{~K}$ and step of $25 \mathrm{~K}$. The thermal diffusivity $(\alpha)$ and specific heat $\left(\mathrm{C}_{\mathrm{p}}\right)$ of disk-shaped samples coated with graphite were obtained using the pulsed laser flash method (LFA-457, Netzsch) with 3 laser shots average, from room temperature up to $873 \mathrm{~K}$, a step of $25 \mathrm{~K}$, and performed after 2 min of steady-state, under $\mathrm{N}_{2}$ atmosphere. The thermal conductivity ( $\kappa)$ of the samples was calculated from the measured $\alpha, C_{p}$, and $\varrho$ using Eq. A, as follows:

$$
\kappa=\alpha \cdot C_{p} \cdot Q
$$

\section{RESULTS AND DISCUSSION}

The DTA curves relative to precursors mixture of undoped and doped $\mathrm{Ca}_{3} \mathrm{Co}_{4} \mathrm{O}_{9}$ are presented in Fig. 1. The curves show an exothermic peak close to $440 \mathrm{~K}$, which was assigned to the evaporation of adsorbed water. The strong exothermic reaction observed between 590 and 750 $\mathrm{K}$ was due to the combustion of the organic compounds from citric acid [21]. Above $790 \mathrm{~K}$, oxidation reactions and crystal formation occurred. According to DTA analysis, the formation process of $\mathrm{Ca}_{3} \mathrm{Co}_{4} \mathrm{O}_{9}$ can be described as the removal of organic phase by calcination to form $\mathrm{CaO}$ and $\mathrm{CoO}$, then the oxidation of $\mathrm{CoO}$ to $\mathrm{Co}_{3} \mathrm{O}_{4}$ by heating in the air, and finally, the reaction of inorganic oxides [16]. From

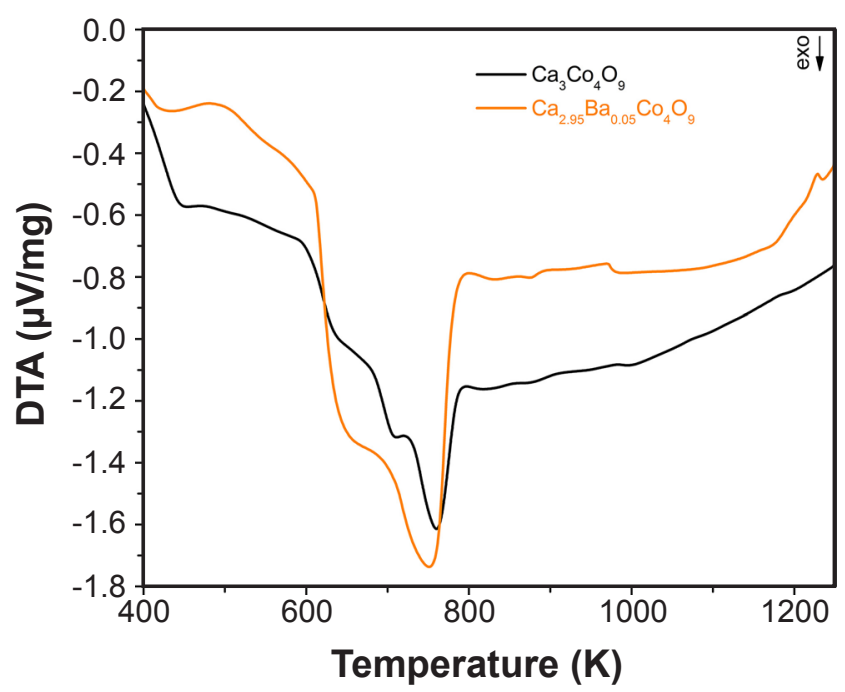

Figure 1: DTA curves of undoped and 0.05 Ba-doped CCO powders obtained by simplified chemical route. 


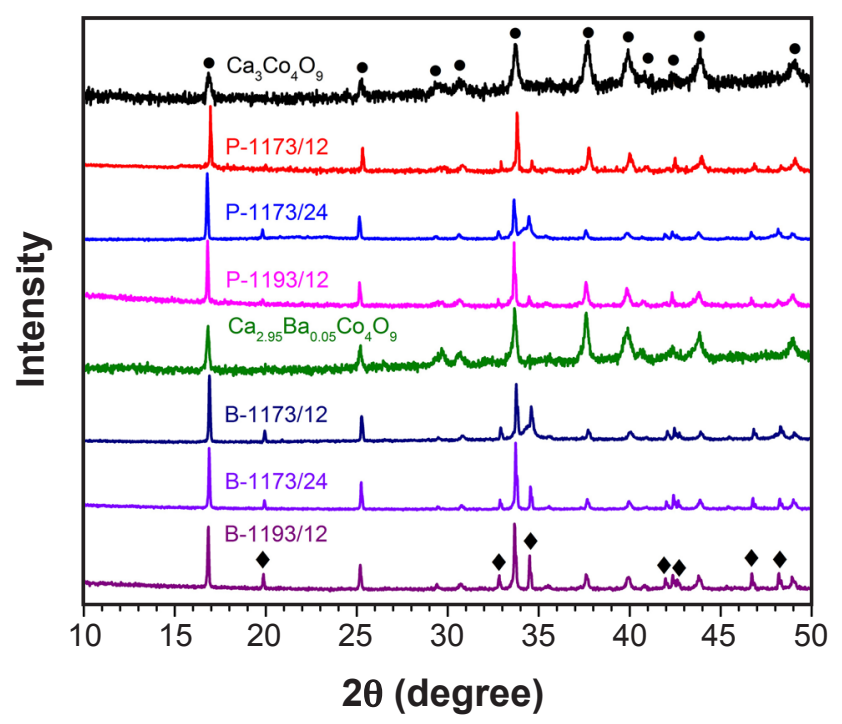

Figure 2: X-ray diffraction patterns of undoped and 0.05 Ba-doped $\mathrm{Ca}_{3} \mathrm{Co}_{4} \mathrm{O}_{9}$ powders and ceramics. Peaks of $\mathrm{Ca}_{3} \mathrm{Co}_{4} \mathrm{O}_{9}$ phase are marked with $\bullet$; $\mathrm{Ca}_{3} \mathrm{Co}_{2} \mathrm{O}_{6}$ peaks are marked with $\bullet$.

the curves, it was possible to observe that the chemical reactions were completely finished at $1073 \mathrm{~K}$, which was the temperature adopted as a reference for calcination. Furthermore, it should be noted that the $\mathrm{Ca}_{3} \mathrm{Co}_{4} \mathrm{O}_{9}$ ceramic sintering temperature should not be higher than $1208 \mathrm{~K}$. Above this temperature, $\mathrm{Ca}_{3} \mathrm{Co}_{4} \mathrm{O}_{9}$ partially decomposes into $\mathrm{Ca}_{3} \mathrm{Co}_{2} \mathrm{O}_{6}$, whose electrical resistivity is higher than that for $\mathrm{Ca}_{3} \mathrm{Co}_{4} \mathrm{O}_{9}$ [22].

Fig. 2 displays similar XRD patterns for undoped and doped $\mathrm{Ca}_{3} \mathrm{Co}_{4} \mathrm{O}_{9}$ powders. This analysis showed that only the $\mathrm{Ca}_{3} \mathrm{Co}_{4} \mathrm{O}_{9}$ phase was present after calcination, according to JCPDS file 23-110, even with $\mathrm{Ba}$ addition into CCO composition. Constantinescu et al. [10] attributed this effect to the fact that $\mathrm{Ba}^{2+}$ ions have mainly entered into the $\mathrm{Ca}_{3} \mathrm{Co}_{2} \mathrm{O}_{\mathrm{y}}$ structure, substituting calcium ions in the $\mathrm{b}_{2}$-axis ( $\left[\mathrm{Ca}_{2} \mathrm{CoO}_{3}\right]$ type layers), once it is considerably larger than the $\mathrm{b}_{1}$-axis (corresponding to the $\left[\mathrm{CoO}_{2}\right]$ layer). On the other hand, Carvillo et al. [11] observed the segregation of $\mathrm{Ba}$ ion at the grain boundary, not being incorporated in the $\mathrm{CCO}$ structure. Regarding the sintered samples, Fig. 2 shows that the major peaks in XRD patterns are associated with the $\mathrm{Ca}_{3} \mathrm{Co}_{4} \mathrm{O}_{9}$ phase, in agreement with previously reported data [10]. Some peaks of the $\mathrm{Ca}_{3} \mathrm{Co}_{2} \mathrm{O}_{6}$ phase (JCPDS file 21-0139, shown as in Fig. 2) could be observed on XRD patterns for both undoped and doped ceramics, being more evident in the last. It suggested that $\mathrm{Ba}^{2+}$ addition caused a slight increase in $\mathrm{Ca}_{3} \mathrm{Co}_{2} \mathrm{O}_{6}$ phase content. However, in the Ba-doped samples, there is no noticeable effect on peak displacement related to the distortion of the structure, neither in $\mathrm{Ca}_{3} \mathrm{Co}_{4} \mathrm{O}_{9}$ nor in $\mathrm{Ca}_{3} \mathrm{Co}_{2} \mathrm{O}_{6}$ phases, probably due to the small amount of doping with Ba ion [10], or, more likely, due to the segregation of barium ions in the grain boundary [11]. Furthermore, Ba segregation at grain boundaries could be attributed to the mismatch size effect of the ionic radius in the lattice. The ionic radius of $\mathrm{Ba}^{2+}$ is $149 \mathrm{pm}$, significantly larger than those for $\mathrm{Ca}^{2+}(114 \mathrm{pm})$ or $\mathrm{Co}^{3+}(68.5 \mathrm{pm})$ ions [23], preventing $\mathrm{Ba}^{2+}$ ions to fit in the sites occupied by those ions. Based on the $\mathrm{Ca}-\mathrm{Co}-\mathrm{O}$ phase diagram [22], the $\mathrm{Ca}_{3} \mathrm{Co}_{2} \mathrm{O}_{6}$ phase formation started at $\sim 1070 \mathrm{~K}$, close to calcination temperature. Moreover, a rich oxygen atmosphere during calcination and sintering can stabilize the $\mathrm{Ca}_{3} \mathrm{Co}_{4} \mathrm{O}_{9}$ phase [24], avoiding $\mathrm{CCO}$ decomposition into $\mathrm{Ca}_{3} \mathrm{Co}_{2} \mathrm{O}_{6}$ and $\mathrm{CoO}$, according to Eq. B. As the second phase could be observed on XRD only for ceramics, it follows that the decomposition of the $\mathrm{Ca}_{3} \mathrm{Co}_{4} \mathrm{O}_{9}$ phase mainly occurred during the sintering process for both compositions, due to higher temperature and air atmosphere.

$$
\mathrm{CCO} \rightarrow \mathrm{Ca}_{3} \mathrm{Co}_{2} \mathrm{O}_{6}+2 \mathrm{CoO}+\frac{1}{2} \mathrm{O}_{2}(\mathrm{~g})
$$

Table I shows the apparent densities for all ceramics. Density values for undoped ceramics were between 3.10 and $3.60 \mathrm{~g} / \mathrm{cm}^{3}$, while for doped ceramics, the values were between 3.52 and $3.73 \mathrm{~g} / \mathrm{cm}^{3}$. The sintering condition at $1193 \mathrm{~K}$ for $12 \mathrm{~h}$ produced ceramics with the highest densification values for both compositions, that is, undoped and doped ceramics. Compared to the theoretical density value of $4.677 \mathrm{~g} / \mathrm{cm}^{3}$ for $\mathrm{Ca}_{3} \mathrm{Co}_{4} \mathrm{O}_{9}$ ceramic [25], the highest relative densities were about $77 \%$ and $80 \%$ for undoped (P-1193/12) and doped (B-1193/12) ceramics, respectively. Constantinescu et al. [10] produced undoped and Ba-doped $\mathrm{CCO}$ ceramics through solid-state reaction and the apparent densities for ceramics sintered at $1173 \mathrm{~K}$ for $24 \mathrm{~h}$ ranged from $72 \%$, for the undoped ceramics, to $77 \%$, for the $0.05 \mathrm{Ba}$ doped ones. This indicated that raising sintering temperature by only $20 \mathrm{~K}$, from 1173 to $1193 \mathrm{~K}$, could improve the densification process and shorten sintering time.

Table I - Apparent and relative densities, mean particle/grain sizes, and standard deviations of powders and ceramics.

\begin{tabular}{cccc}
\hline Sample & $\begin{array}{c}\text { Apparent } \\
\text { density } \\
\left(\mathrm{g} / \mathrm{cm}^{3}\right)\end{array}$ & $\begin{array}{c}\text { Relative } \\
\text { density } \\
(\%)\end{array}$ & $\begin{array}{c}\text { Particle/ } \\
\text { grain size } \\
(\mathrm{nm})\end{array}$ \\
\hline $\begin{array}{c}\text { Undoped CCO } \\
\text { powder }\end{array}$ & - & - & $525 \pm 116$ \\
$\mathrm{P}-1173 / 12$ & 3.10 & 66 & $1213 \pm 293$ \\
$\mathrm{P}-1173 / 24$ & 3.25 & 69 & $1391 \pm 245$ \\
$\mathrm{P}-1193 / 12$ & 3.60 & 77 & $1734 \pm 402$ \\
$\begin{array}{c}\text { Doped CCO } \\
\text { powder }\end{array}$ & - & - & $521 \pm 97$ \\
$\mathrm{~B}-1173 / 12$ & 3.52 & 75 & $909 \pm 312$ \\
$\mathrm{~B}-1173 / 24$ & 3.57 & 76 & $1262 \pm 262$ \\
$\mathrm{~B}-1193 / 12$ & 3.73 & 80 & $1452 \pm 287$ \\
\hline
\end{tabular}

Fig. 3 shows SEM micrographs of CCO particles. Particles seemed to be strongly agglomerated in both undoped (Fig. 3a) and doped (Fig. 3e) CCO powders. Typical features of the chemical synthesis route can also be distinguished in the micrographs, composed of randomly oriented plate-like 
particles of different sizes, even with Ba-doping. Fig. 3 also presents SEM micrographs of the surfaces of P-1173/12 (Fig . 3b), P-1173/24 (Fig. 3c), P-1193/12 (Fig. 3d), B-1173/12 (Fig. 3f), B-1173/24 (Fig. 3g), and B-1193/12 (Fig. 3h) ceramics. The apparent thickness along the $\mathrm{c}$-axis was given by the stacking of very thin plate-like grains of $\mathrm{Ca}_{3} \mathrm{Co}_{4} \mathrm{O}_{9}$ [26], which confirmed that the preferential crystal-growth is produced along the $\mathrm{a}-\mathrm{b}$ crystallographic plane. Also, it can be seen that the porosity decreased when barium was present. Table I presents mean particle size values, which were around $520 \mathrm{~nm}$ for both powders, and also shows grain size for undoped and doped ceramics. It has been found that grain sizes measured in the planar dimensions were in the range of 1213 to $1734 \mathrm{~nm}$ for undoped ceramics. The grain sizes for Ba-doped ceramics were between 909 and 1452 $\mathrm{nm}$, being in agreement with other works in the literature $[10,26]$. However, a slight decrease in the grain size of Ba-doped ceramics can be detected as a consequence of a small amount of liquid phase that could have enhanced the densification during the sintering process. The mechanism of the liquid phase sintering process originated from the solution-reprecipitation processing could suppress the coarsening of grain growth, producing a finer microstructure for Ba-doped ceramics [27]. As also confirmed by EDS analysis, undoped ceramics were mainly composed by the $\mathrm{Ca}_{3} \mathrm{Co}_{4} \mathrm{O}_{9}$ phase, and $\mathrm{Ba}$ ion was not identified due to its very low concentration in the samples.

Fig. 4 shows the temperature dependence of the electrical conductivity $(\sigma)$ for the ceramics. In comparison with P-1193/12 ceramic, some increase of $\sigma$ was obtained by B-1193/12 ceramic from 6200 to around $7000 \mathrm{~S} / \mathrm{m}$ at $873 \mathrm{~K}$. Electrical conductivity values between 6500 and $8500 \mathrm{~S} / \mathrm{m}$ at $873 \mathrm{~K}$ were found for undoped CCO produced by sol-gel route
[28] and coprecipitation method [17] for ceramics sintered at $1173 \mathrm{~K}$ for $24 \mathrm{~h}$. This work shows that Ba-doping associated with a simplified methodology can lead to values of electrical conductivity close to those obtained from complex synthesis methods. Higher sintering temperature favors grain growth for both undoped and doped ceramics, as can be noted in Table I. Although Ba-doped ceramics exhibit a finer microstructure, P-1193/12 and B-1193/12 ceramics were denser than the others, which favored the electrical conductivity due to reduced porosity [29]. Also, as discussed before, barium doping reduced the porosity of the ceramics, which enhanced $\sigma$ values. The P-1173/12 ceramic body had a relative density of $66 \%$ and the lowest $\sigma$, whereas B-1173/12 reached $5500 \mathrm{~S} / \mathrm{m}$ at $873 \mathrm{~K}$ due to a $9 \%$ increase in relative density.

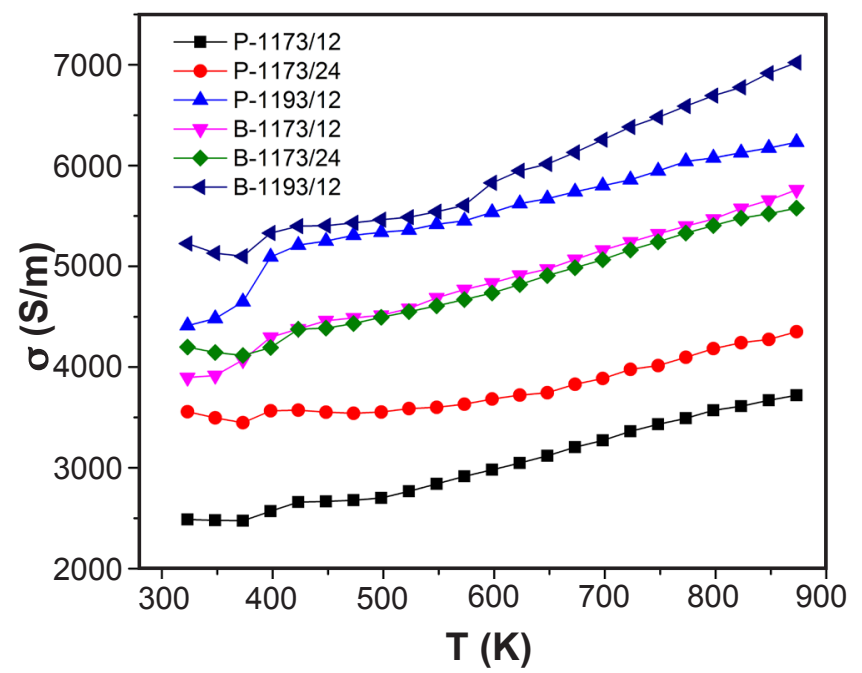

Figure 4: Electrical conductivity $(\sigma)$ as a function of temperature for undoped and $0.05 \mathrm{Ba}$-doped CCO ceramics up to $873 \mathrm{~K}$.
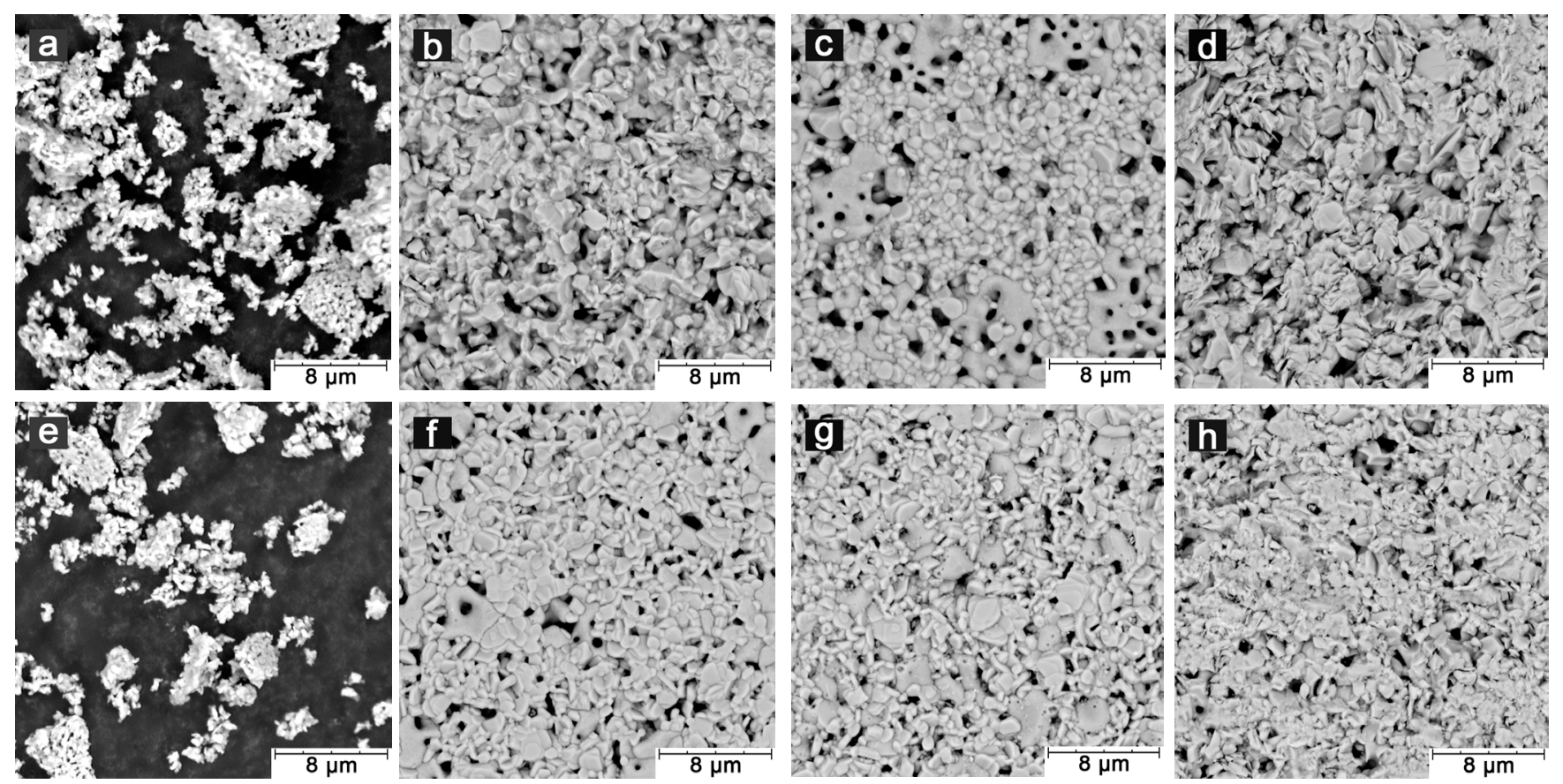

Figure 3: SEM micrographs of $\mathrm{Ca}_{3} \mathrm{Co}_{4} \mathrm{O}_{9}$ particles (a), and undoped bodies sintered at $1173 \mathrm{~K} / 12 \mathrm{~h}$ (b), $1173 \mathrm{~K} / 24 \mathrm{~h}$ (c), and $1193 \mathrm{~K} / 12 \mathrm{~h}$ (d); $\mathrm{Ca}_{2.95} \mathrm{Ba}_{0.05} \mathrm{Co}_{4} \mathrm{O}_{9}$ particles (e), and doped bodies sintered at $1173 \mathrm{~K} / 12 \mathrm{~h}(\mathrm{f}), 1173 \mathrm{~K} / 24 \mathrm{~h}(\mathrm{~g})$, and $1193 \mathrm{~K} / 12 \mathrm{~h}(\mathrm{~h})$. 
At $600 \mathrm{~K}$ the $\mathrm{CCO}$ ceramics show small polaron conducting behavior, where the charge transport process in this system is a hole hopping from $\mathrm{Co}^{4+}$ to $\mathrm{Co}^{3+}$ [17]. At higher temperatures, there is a change to a semiconducting mechanism. According to the polaron theory, the electrical conductivity of a small polaron hopping conduction mechanism can be written as:

$$
\sigma=\text { n.e. } \cdot \mathrm{a}^{2} \frac{\mathrm{A}}{\mathrm{T}} \exp \frac{-\mathrm{E}_{\mathrm{p}}}{\mathrm{K}_{\mathrm{B}} \cdot \mathrm{T}}
$$

where $\mathrm{n}, \mathrm{e}, \mathrm{a}, \mathrm{E}_{\mathrm{p}}, \mathrm{K}_{\mathrm{B}}$, and $\mathrm{A}$ are the carrier concentration, the electron charge of the carrier, the intersite distance of hopping, the polaron activation energy, the Boltzmann constant, and a pre-exponential term related to the scattering mechanism, respectively [9]. For materials with semiconducting behavior, the electrical conductivity can be described by the Arrhenius equation as:

$$
\sigma=\sigma_{0} \exp \frac{-E_{a}}{\mathrm{~K}_{\mathrm{B}} \cdot \mathrm{T}}
$$

where $\sigma_{0}$ is the pre-exponential term and $\mathrm{E}_{\mathrm{a}}$ is the Arrhenius activation energy. Linear relationships can be obtained at two temperature ranges: below $600 \mathrm{~K}$, representing the small polaron-hopping conduction mechanism [15]; and above $600 \mathrm{~K}$, indicating the semiconducting mechanism. As shown in Fig. 5, the $\mathrm{E}_{\mathrm{p}}$ and $\mathrm{E}_{\mathrm{a}}$ activation energies were obtained from a plot of $\ln (\sigma \mathrm{T})$ or $\ln (\sigma)$ versus $1000 / \mathrm{T}$, respectively. Table II presents the $\mathrm{E}_{\mathrm{p}}$ and $\mathrm{E}_{\mathrm{a}}$ values for every ceramic, related to each carrier conducting behavior. $\mathrm{E}_{\mathrm{p}}$ values were lower than previously reported values for the $\mathrm{CCO}$ system ranging from 0.066 to $0.085 \mathrm{eV}$ for $\mathrm{K}$ [9] and $\mathrm{Bi}$ [27] doped ceramics. It was noted that the $\mathrm{E}_{\mathrm{a}}$ values were lower than the $\mathrm{E}_{\mathrm{p}}$ values, which can be associated with higher carrier transport efficiency by semiconducting mechanism than polaron mechanism. It is known that polaron mobility is reduced since the binding energy of the carrier to the polarized lattice must be overcome, becoming highly

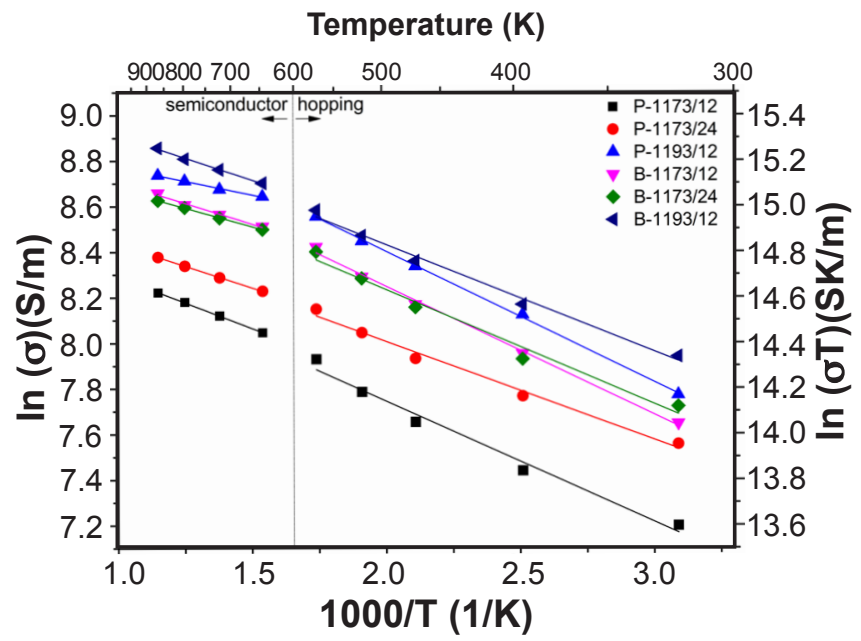

Figure 5: Activation energy plots of electrical conductivity for undoped and $0.05 \mathrm{Ba}$-doped CCO ceramics. The lines are linearly fitted using a least-squares method. temperature-dependent. In this case, the polaron presents higher activation energy than a semiconductor material, where the electrons in the conduction band and holes in the valence band may be considered as quasi-free particles [30]. Moreover, both undoped and doped ceramics presents almost the same range of activation energy values, which can indicate that Ba-doping does not alter the electronic structure of the ceramics, once it may be segregated in the grain boundary [11].

Table II - Arrhenius $\left(\mathrm{E}_{\mathrm{a}}\right)$ and polaron $\left(\mathrm{E}_{\mathrm{p}}\right)$ activation energy for undoped and doped ceramics.

\begin{tabular}{ccc}
\hline Ceramic & $\mathrm{E}_{\mathrm{p}}(\mathrm{eV})$ & $\mathrm{E}_{\mathrm{a}}(\mathrm{eV})$ \\
\hline $\mathrm{P}-1173 / 12$ & 0.046 & 0.039 \\
$\mathrm{P}-1173 / 24$ & 0.037 & 0.033 \\
$\mathrm{P}-1193 / 12$ & 0.050 & 0.021 \\
$\mathrm{~B}-1173 / 12$ & 0.049 & 0.032 \\
$\mathrm{~B}-1173 / 24$ & 0.043 & 0.028 \\
$\mathrm{~B}-1193 / 12$ & 0.040 & 0.034 \\
\hline
\end{tabular}

Fig. 6a shows the thermal conductivity $(\kappa)$ of the ceramics and its temperature dependence. There was a reduction in thermal conductivity with increasing temperature due to increased vibrations, which reduced phonon mean free path. As mentioned, Ba-ion doping enhanced electrical conductivity by increasing the density of the ceramics. Although grain growth promoted by high sintering temperature at $1193 \mathrm{~K}$ favored electrical conductivity, denser bulks also favored the enhancement of thermal conductivities, which had a negative impact on the thermoelectric performance of the ceramic. Thus, the plots on Fig. 6a are in agreement with density values presented in Table I. Carvillo et al. [11] produced doped ceramics with $\kappa$ values between 1.7 and $1.8 \mathrm{~W} \cdot \mathrm{m}^{-1} \cdot \mathrm{K}^{-1}$ at $\sim 870 \mathrm{~K}$. They observed that Ba-doping reduced the thermal conductivity of $\mathrm{Ca}_{3} \mathrm{Co}_{4} \mathrm{O}_{9}$ ceramics mainly due to phonon scattering enhanced by $\mathrm{Ba}$ ion segregation in the grain boundary, but the effect of doping on density and grain size was not evaluated. For undoped ceramics produced by conventional [11], microwave [31], or cold sintering process [18], the thermal conductivity is about $2.38,1.38$, and $0.98 \mathrm{~W} \cdot \mathrm{m}^{-1} \cdot \mathrm{K}^{-1}$, respectively, which are in agreement with the values obtained in this work.

As shown in Fig. 6b, the Seebeck coefficient values for P-1173/24, P-1193/12, B-1173/12, and B-1173/24 ceramics presented almost the same values (from 111 to $116 \mu \mathrm{V} / \mathrm{K}$ ) and near typical to the ones reported in the literature $(\sim 125 \mu \mathrm{V} / \mathrm{K})$ at room temperature [4]. On the other hand, P-1173/12 ceramic showed a slightly different behavior, which had a higher Seebeck value $(130 \mu \mathrm{V} / \mathrm{K})$ at room temperature. The B-1193/12 ceramic, which presented the highest density and electrical conductivity, also presented the lowest Seebeck value at room temperature. At $873 \mathrm{~K}$, higher Seebeck values in the range of 130 to $140 \mu \mathrm{V} / \mathrm{K}$ were observed for undoped samples, while Ba-doping 

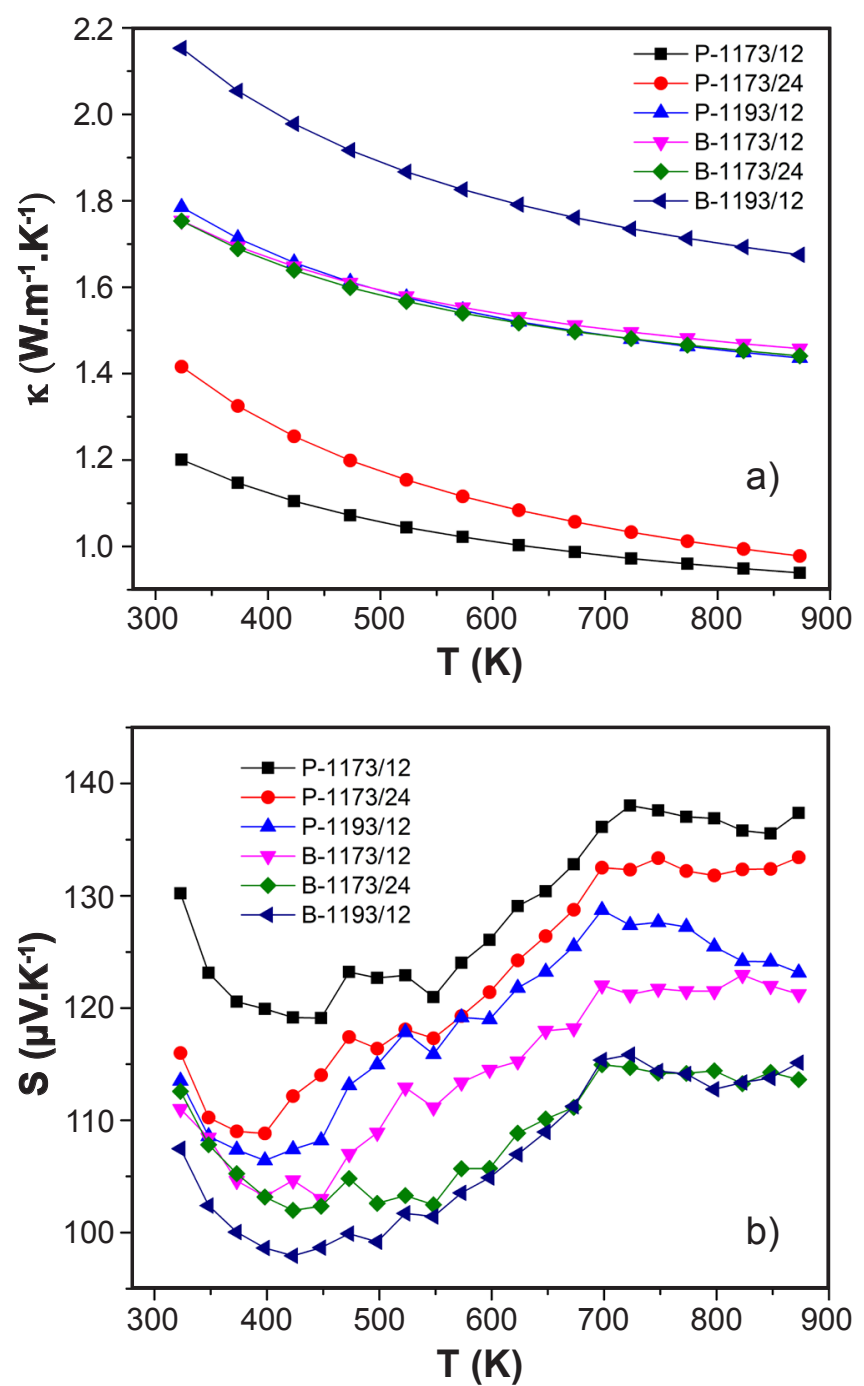

Figure 6: Thermal conductivity, $\kappa$ (a), and Seebeck coefficient, S (b), as a function of temperature for undoped and 0.05 Ba-doped CCO ceramics up to $873 \mathrm{~K}$.

reduced its value. In literature, Seebeck coefficient values for CCO ceramics can vary between 100 and $200 \mu \mathrm{V} / \mathrm{K}$ [24, 27, 31, 32], but also, values lower than $100 \mu \mathrm{V} / \mathrm{K}[18,29]$ are observed. The reduction in Seebeck coefficient can be attributed to high charge carrier concentration in materials, which leads to an increase in electrical conductivity [33]. Another issue that can affect Seebeck coefficient values is the grain size [34]; when the grain size decreases, $S$ values can also be reduced. However, the concentration of charge carriers can decrease with increasing porosity, and cause a moderate increase in S values [24]. In the present study, doped ceramics presented higher density, lower grain size, and higher electrical conductivity values in comparison to undoped ceramics. The association of these factors contributed to reducing the Seebeck coefficient values in doped ceramics.

Fig. 7a shows that benefiting from both the increased $\mathrm{S}$ and $\sigma, \mathrm{P}-1193 / 12$ ceramic reached the highest power factor $\left(\mathrm{PF}=\mathrm{S}^{2} \sigma\right.$ ) of $0.10 \mathrm{~mW} \cdot \mathrm{m}^{-1} \cdot \mathrm{K}^{-2}$ at $873 \mathrm{~K}$, immediately followed by B-1193/12 ceramic $\left(0.09 \mathrm{~mW} \cdot \mathrm{m}^{-1} \cdot \mathrm{K}^{-2}\right.$ at $\left.873 \mathrm{~K}\right)$ due to the higher $\sigma$ value. This behavior is explained by the fact that Ba-doping reduces $\mathrm{S}$, which has a quadratic relation with PF. Gunes and Ozenbas [29] produced undoped CCO ceramics by a more complex sol-gel method with reflux adding $0,3 \%, 5 \%$, and $7 \%$ of polyethylene glycol (PEG). In this study, the authors found PF values ranging from 0.10 to $0.16 \mathrm{~mW} \cdot \mathrm{m}^{-1} \cdot \mathrm{K}^{-2}$ at $873 \mathrm{~K}$, increasing with the percentage of PEG. In the study of CCO ceramics obtained by solid-state reaction [10], the PF value for the $0.05 \mathrm{Ba}$-doped sample was $0.21 \mathrm{~mW} \cdot \mathrm{m}^{-1} \cdot \mathrm{K}^{-2}$ at $873 \mathrm{~K}$. On the other hand, through non-stoichiometric addition of $\mathrm{Ba}, \mathrm{Ca}_{3} \mathrm{Ba}_{0.05} \mathrm{Co}_{4} \mathrm{O}_{9}$ ceramics prepared by a sol-gel chemical solution route exhibited a PF higher than $0.80 \mathrm{~mW} \cdot \mathrm{m}^{-1} \cdot \mathrm{K}^{-2}$ at $873 \mathrm{~K}$ [11]. In these studies, the grain size of the ceramics was not evaluated by the authors $[10,11]$, but was estimated based on published SEM images, being bigger than $2 \mu \mathrm{m}$, higher than those obtained in this study. Smaller grain size can reduce the electrical conductivity of the $\mathrm{CCO}$ ceramics [18], and in this case, can be related between Table I and Fig. 4, decreasing the PF values of the ceramics as noted in Fig. 7a.
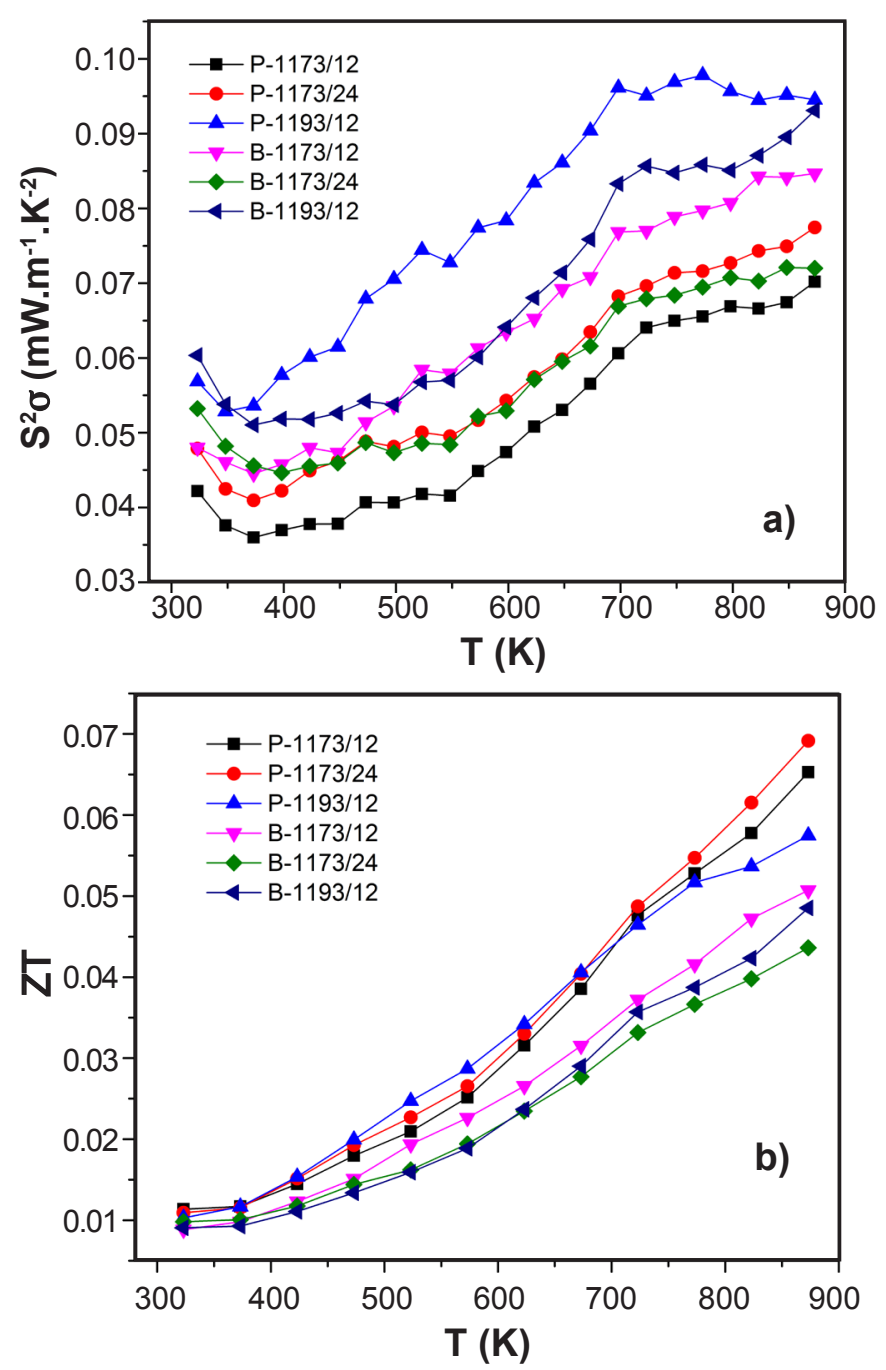

Figure 7: Power factor, $\mathrm{S}^{2} \sigma$ (a), and figure of merit, ZT (b), as a function of temperature for undoped and 0.05 Ba-doped CCO ceramics up to $873 \mathrm{~K}$. 
The plots of the dimensionless figure of merit (ZT) as a function of temperature are shown in Fig. 7b. ZT is related to efficiency conversion and can be calculated using Eq. E. It can be seen that undoped ceramics presented higher ZT values than doped ones. Despite the electrical conductivity improvement, Ba-doping also produced ceramics with higher thermal conductivity, due to the increase in density. It can be seen that the increase in thermal conductivity and Seebeck coefficient reduction were more significant than the electrical conductivity improvement, which is harmful to increase ZT values, based on Eq. E. As a result, the maximum ZT value for a doped ceramic was 0.05 at $873 \mathrm{~K}$ (B-1173/12). At last, the highest overall $\mathrm{ZT}$ value was 0.07 for the P-1173/24 ceramic at $873 \mathrm{~K}$. Highest ZT achieved for pure calcium cobaltite samples was around 0.16 at 773 $\mathrm{K}$ produced by sol-gel and spark plasma sintering [35]. In the study performed by Carvillo et al. [11], they obtained ZT values of 0.21 and 0.52 at $1023 \mathrm{~K}$ for undoped and doped ceramics, respectively. Besides the additionally doping methodology, the ceramics were produced in an oxygen atmosphere, which substantially increased the electrical conductivity, and consequently, increased the ZT values of the ceramics.

$$
\mathrm{ZT}=\frac{\mathrm{S}^{2} \cdot \sigma}{\kappa} \mathrm{T}
$$

\section{CONCLUSIONS}

The effects of the simplified chemical route, barium doping, and sintering conditions on the thermoelectric properties of the calcium cobaltite system were investigated by means of relative density, grain size, electrical and thermal conductivity, Seebeck coefficient, power factor, and ZT. The Ba-doped CCO ceramics showed higher densities and higher electrical conductivity when sintered at $1193 \mathrm{~K}$ for $12 \mathrm{~h}$. Undoped and doped ceramics presented almost the same range of activation energy values, which can indicate that Ba-doping does not alter the electronic structure of the ceramics, once it may be segregated in the grain boundary. As the densification and grain size had a more significant impact on electrical conductivity, ceramics with higher density and grain size showed a higher power factor, e.g., $0.10 \mathrm{~mW} \cdot \mathrm{m}^{-1} \cdot \mathrm{K}^{-2}$ at $873 \mathrm{~K}$ for P-1193/12 (undoped sample sintered at $1193 \mathrm{~K}$ for $12 \mathrm{~h}$ ). Since the preparation methods can drastically influence the final bulk properties of $\mathrm{CCO}$ ceramics, the simplified method developed in this work was suitable to produce undoped $\mathrm{CCO}$ ceramics with ZT up to 0.07 at $873 \mathrm{~K}$, unlike substitutional Ba-doped ones, mainly due to non-effective substitution reflected on lower Seebeck coefficient values.

\section{ACKNOWLEDGMENTS}

This study was supported by CNPq (National Council for Scientific and Technological Development of Brazil), Proc: 307397/2017-3 and Proc: 312640/2017-0. ANP (National Agency of Petroleum, Natural Gas and Biofuels of
Brazil), and Shell of Brazil, through the Clause Investment in Research, Development, and Innovation, contained in the contracts for Exploration, Development and Production of Oil and Natural Gas also supported this study.

\section{REFERENCES}

[1] S. Jantrasee, P. Moontragoon, S. Pinitsoontorn, J. Semicond. 37, 9 (2016) 92002.

[2] M.A. Mohammed, S. Izman, A.M. Noor, S. Rajoo, M.B . Uday, N.H. Obayers, M.F. Omar, Int. J. Eng. Technol. 7, 2.29 (2018) 31.

[3] I. Terasaki, Y. Sasago, K. Uchinokura, Phys. Rev. B 56, 20 (1997) 685.

[4] S. Lemal, J. Varignon, D.I. Bilc, P. Ghosez, Phys. Rev. B 95, 7 (2017) 75205.

[5] M. Molinari, D.A. Tompsett, S.C. Parker, F. Azough, R. Freer, J. Mater. Chem. A 2 (2014) 14109.

[6] D. Srivastava, C. Norman, F. Azough, M.C. Schäfer, E. Guilmeau, R. Freer, J. Alloys Compd. 731 (2018) 723.

[7] M.A. Mohammed, S. Izman, A.M. Noor, S. Rajoo, M.B. Uday, N.H. Obayers, M.F. Omar, Int. J. Eng. Technol. 7, 2.29 (2018) 27.

[8] G. Constantinescu, S. Rasekh, M.A. Torres, P. Bosque, J.C. Diez, M.A. Madre, A. Sotelo, Ceram. Int. 41, 9 (2015) 10897.

[9] S.-M. Choi, C.-H. Lim, W.-S. Seo, J. Korean Phys. Soc. 57, 4 (2010) 1054.

[10] G. Constantinescu, S. Rasekh, M.A. Torres, M.A. Madre, A. Sotelo, J.C. Diez, J. Mater. Sci. Mater. Electron. 26, 6 (2015) 3466.

[11] P. Carvillo, Y. Chen, C. Boyle, P.N. Barnes, X. Song, Inorg. Chem. 54, 18 (2015) 9027.

[12] C. Boyle, L. Liang, Y. Chen, J. Prucz, E. Cakmak, T.R. Watkins, E. Lara-Curzio, X. Song, Ceram. Int. 43, 14 (2017) 11523.

[13] Q.M. Lu, J.X. Zhang, Q.Y. Zhang, Y.Q. Liu, D.M. Liu, $25^{\text {th }}$ Int. Conf. Thermoelectr. 9 (2006) 66.

[14] F. Kahraman, M.A. Madre, S. Rasekh, C. Salvador, P. Bosque, M.A. Torres, J.C. Diez, A. Sotelo, J. Eur. Ceram. Soc. 35, 14 (2015) 3835.

[15] Y. Zheng, H. Zhou, T. Ma, G. Zuo, H. Li, T. Su, C. Wu, H. Huang, D. Wang, L. Yin, Bull. Mater. Sci. 37, 5 (2014) 963.

[16] J. Xu, C. Wei, K. Jia, J. Alloys Compd. 500, 2 (2010) 227.

[17] A. Sotelo, S. Rasekh, M.A. Torres, P. Bosque, M.A. Madre, J.C. Diez, J. Solid State Chem. 221 (2015) 247.

[18] A.M. dos Santos, D. Thomazini, M.V. Gelfuso, Ceram. Int. 46, 9 (2020) 14064.

[19] S. Katsuyama, Y. Takiguchi, M. Ito, Mater. Trans. 48, 8 (2007) 2073.

[20] ASTM B962, "Standard test methods for density of compacted or sintered powder metallurgy (PM) products using Archimedes' principle", ASTM Int. (2017).

[21] C. Masingboon, P. Thongbai, S. Maensiri, T. Yamwong, S. Seraphin, Mater. Chem. Phys. 109, 2-3 (2008) 262. 
[22] D. Sedmidubský, V. Jakeš, O. Jankovský, J. Leitner, Z. Sofer, J. Hejtmánek, J. Solid State Chem. 194 (2012) 199.

[23] R.D. Shannon, Acta. Crystallogr. A32 (1976) 751.

[24] N. Kanas, S.P. Singh, M. Rotan, M. Saleemi, M. Bittner, A. Feldhoff, T.E. Norby, K. Wiik, T. Grande, M.-A. Einarsrud, J. Eur. Ceram. Soc. 38, 4 (2018) 1592.

[25] Y.C. Liou, W.C. Tsai, W.Y. Lin, U.R. Lee, J. Aust. Ceram. Soc. 44 (2008) 17.

[26] X. Song, Y. Chen, S. Chen, E. Barbero, E.L. Thomas, P. Barnes, Solid State Commun. 152, 16 (2012) 1509.

[27] Z. Shi, F. Gao, J. Zhu, J. Xu, Y. Zhang, T. Gao, M. Qin, J. Mater. 5, 4 (2019) 711.

[28] A. Sotelo, G. Constantinescu, S. Rasekh, M.A. Torres, J.C. Diez, M.A. Madre, J. Eur. Ceram. Soc. 32, 10 (2012) 2415 .
[29] M. Gunes, M. Ozenbas, J. Alloys Compd. 626 (2015) 360. [30] W.D.Kingery, H.K. Bowen, D.R. Uhlmann, Introduction to ceramics, Wiley Intersci., New York (1976) 1032.

[31] K. Miyazawa, F. Amaral, A.V. Kovalevsky, M.P.F. Graça, Ceram. Int. 42, 8 (2016) 9482.

[32] F. Delorme, P. Diaz-Chao, E. Guilmeau, F. Giovannelli, Ceram. Int. 41, 8 (2015) 10038.

[33] J.P. Heremans, V. Jovovic, E.S Toberer, A. Saramat, K. Kurosaki, A. Charoenphakdee, S. Yamanaka, G.J. Snyder, Science 321, 5888 (2008) 554.

[34] R.Z. Zhang, K. Koumoto, J. Electron. Mater. 42 (2013) 1568.

[35] T. Yin, D. Liu, Y. Ou, F. Ma, S. Xie, J. Li, J. Li, J. Phys. Chem. C 114, 21 (2010) 10061.

(Rec. 15/06/2020, Rev. 28/07/2020, 21/08/2020, Ac. 26/08/2020)

(CC) BY-NC 